\title{
The best time to talk about death
}

\author{
Lodovico Balducci ${ }^{1}$
}

Received: 9 June 2015/ Accepted: 10 June 2015/Published online: 15 July 2015

(C) Springer-Verlag Italia 2015

The scope of this issue is very diverse, as it spaces from discussion of death and dying to the experience of a rural dental clinic, to the evaluation of child nutrition through photography. As it has been always the case since I have been at the helm of the Journal, each topic is relevant to the delivery of personalized medicine and each one would deserve a separate editorial.

I elected to comment the article of Roscoe and Tullis, as it involves a daily medical question that has been vexing for generations of physicians: "when is it the right time to discuss death with a patient?" Both authors are trained in qualitative research, and Jillian Tullis has discussed in her doctoral dissertation the experience of dying, after spending 1 year in recording the conversations of hospice patients with their family and with the hospice staff and after interviewing each one of these people. The article is based on the description of hand-on experience rather than on theoretical considerations and for this reason its practical implications are very valuable.

The conclusions of the authors are surprising and somehow challenging, as they counter the common medical practice as well as the common lifestyle, both intent to escape the possibility of death and to disregard the presence of death like one would try to disregard a horse on the dinner table. How many times, during my earliest medical years, did I say to a patient whose cancer had progressed beyond any possible treatment: "go home, try to eat well and to do some exercise, and when you will have gained some weight and some strength we will try a different treatment." This was a classical white lie, that is a lie

\footnotetext{
Lodovico Balducci

lodovico.balducci@moffitt.org

Tampa, USA
}

masqueraded by the truth. I knew very well that the patient would have never gotten better, and so I would have never found myself in the dilemma to institute a new treatment, but I did convey the impression that his condition might have improved while I knew very well that the improvement would have never occurred, short of a miracle. I still don't know why I did lie, whether it was to protect the patient or myself from the disrupting impression of imminent death, to ignore the horse on the dinner table and to pretend we could continue a leisurely convivial conversation despite the horse's overwhelming presence.

The authors hold that death should first be discussed when the patient is healthy and is not affected by a terminal disease. In other words the thought of death should be present throughout one's life. Death should occupy our minds the same way other milestones do, including puberty, growth, graduation, marriage, birth of our offspring, retirement, etc. Though they don't state it explicitly, a corollary of their study is that human beings should learn how to treasure death, the same way they learn how to treasure every human experience. After all, if death is the final enemy, we all are doomed, as we all are going to die. The only way to defeat death is to coopt death as part of life.

The conclusions are backed by a number of stories showing how devastating the revelation of death maybe for individuals who were not ready to receive it. That abrupt revelation may lead to desperation and dissolution of families, friendships and professional bonds. Perhaps more regrettable, people who are not able to face their own death miss a unique opportunity to heal old wounds and to rediscover affections that were considered dead while they were only forgotten as an adolescent's diary at the bottom of a chest. In the movie "Terms of endearment" starring Shirley McClain, a philandering husband and a lonely wife 
renew their wedding vows as the young wife is close to die of breast cancer. Thanks to the same death a mother estranged from her daughter finds again her maternal love, that now she bestows on her grandchildren. Years before she had suggested to her daughter asking for money to abort the little girl who is now the pearl of her eyes.

Another implication of the article is that physicians are in part responsible to prepare their patients to the possibility of death by discussing very early in their relationship patient's values and desires. Of course physicians are not asked to be "angels of death." Thanks to their special relationship to the patients and their knowledge of medicine, they are in a unique position to advise their patients concerning the course of action most suitable to them. But physicians cannot do that without knowing their patients, so that a discussion of values is pertinent to all medical practices. This is even more true today when a patient may see multiple different specialists without the benefits of a primary care provider, that knows the patient from the cradle. I subscribe completely to this suggestion that is indeed consistent with the mission statement of "medicine and the person."

The article illustrates the value of qualitative research in affording realities not amenable to measures, such as the unique feelings that are germane to every human experiences. Educated patients are going to ask more and more questions related to how they are going to live and to die. Physicians cannot afford anymore to ignore these questions, like modern Don Ferrantes pretending that the plague did not exist as it could not be comprehended in their intellectual schemes. Qualitative research, in this case in the form of narrative, allows the medical profession to address these questions.

The authors of this important article fail to address an important issue however: whether it is possible to face death without a transcendent vision of life. They too do ignore a horse on the dinner table, whether religion is a basic human need that gives meaning to all life experiences or instead it is a luxury choice, like buying a pair of Ferragamo shoes at Saks Fifth Avenue. This failure does not impugn the novel message of the authors, that we should start considering death from the moment we are born. I just express the wish that in the future they exploit their considerable talents to discover how one can approach the thoughts and the discussion of death. 